\title{
Two sibs with chorioretinal dystrophy, hypogonadotrophic hypogonadism, and cerebellar ataxia: Boucher-Neuhäuser syndrome
}

\author{
P Rump, B C J Hamel, A J L G Pinckers, P A van Dop
}

\begin{abstract}
We describe two sibs with chorioretinal dystrophy, hypogonadotrophic hypogonadism, and cerebellar ataxia, BoucherNeuhäuser syndrome, a rare but distinct pleiotropic single gene disorder with an autosomal recessive pattern of inheritance. The cases presented illustrate that this syndrome is still poorly recognised. We provide a review and analysis of previously reported cases and the differential diagnosis, which might aid in the identification of additional cases.

( 7 Med Genet 1997;34:767-771)
\end{abstract}

Keywords: Boucher-Neuhäuser syndrome; ataxia; hypogonadism; chorioretinal degeneration

In 1969, Boucher and Gibberd ${ }^{1}$ described two sisters with "a combination of several features which although frequently occurring alone or in pairs, rarely occur all in one patient". The features referred to are chorioretinal degeneration, hypogonadism, and ataxia, which at that time did not "conform to any of the recognised syndromes".

Six years later, Neuhäuser and Opitz ${ }^{2}$ described a new autosomal recessive syndrome combining hypogonadotrophic hypogonadism and cerebellar ataxia. Although ophthalmological examination of two patients described in this study showed retinal pigmentary changes and atrophy, these findings were not considered to be part of the syndrome. The similarities between the cases reported by them and those reported by Boucher and Gibberd ${ }^{1}$ were therefore not recognised until 1989 when Limber et $a l,{ }^{3}$ on re-evaluation of one of the patients described by Neuhäuser and Opitz, ${ }^{2}$ suggested that this was a specific pleiotropic single gene disorder and named it Boucher-Neuhäuser

So far, 17 cases from nine families have been reported, only three of these families in genetic publications. ${ }^{1-10}$ In the present study, we describe two additional cases and after reviewing the published reports list the main clinical characteristics of this rare syndrome and its

The proband, a 31 year old male, was born after a normal pregnancy and delivery. He was seen by an ophthalmologist at the age of 23 years because of slowly progressive visual problems consisting of night blindness and constricting visual fields. His visual acuity was $5 / 10$ in both eyes. Intraocular pressure was 17 $\mathrm{mmHg}$ on the right and $18 \mathrm{mmHg}$ on the left. Fundoscopy showed bilateral atrophy of the retinal pigment epithelium and choriocapillaris in the mid peripheral areas, with peripapillary atrophy and retinal pigment epithelium alterations of the maculae. The electro-oculogram was disturbed bilaterally while electroretinography showed no photopic or scotopic responses at all. A fluorescein angiogram indicated central choriocapillaris atrophy. Colour discrimination was not disturbed. The diagnosis of choroideremia was suggested.

At 25 years of age, he was examined because of poor sexual development. He never needed to shave and although he had erections on awakening no ejaculation occurred. His height was $178 \mathrm{~cm}$ (25th centile) and weight $65 \mathrm{~kg}$ (25th centile). Compared to his trunk, he had relatively long limbs. There was sparse pubic and normal axillary hair with absent chest and facial hair. There was no gynaecomastia and he had a normal masculine voice. He had a very small scrotum and his penis and testicles were small but without anatomical abnormalities. Laboratory tests, including a complete blood count, routine blood chemistry profile, and urine analysis, were within normal limits. Endocrinological studies disclosed hypogonadotrophic hypogonadism. The serum level of testosterone was extremely low $(0.86 \mathrm{nmol} / \mathrm{l}$, normal 10-35) and the concentrations of luteinising hormone (LH) and follicle stimulating hormone (FSH) were below the lowest detectable level $(<1.0 \mathrm{mIU} / \mathrm{ml})$. There was no response to a single intravenous dose of $\mathrm{LH}$ releasing hormone (LH-RH) even after repeated stimulation with LH-RH for one week, suggesting an abnormal pituitary function. The serum levels of oestradiol, cortisol, prolactin, thyroid stimulating hormone (TSH), and thyroxine (T4) were, however, all normal. Bone age, determined according to Greulich and Pyle, was 15 years 6 months. He was treated with intramuscular hormone injections (250 $\mathrm{mg}$ testosterone enantate (Testoviron $(\mathrm{C})$ every four weeks). Subsequently, secondary sex characteristics appeared. There was marked increase in facial and pubic hair growth and ejaculation occurred. Since the site of the hormone injections was troubling the patient, the injections were replaced by oral therapy (testosyndrome. differential diagnosis.

\section{Case reports}

CASE 1

Department of Human
Genetics, University
Hospital Nijmegen, PO
Box 9101, 6500 HB
Nijmegen, The
Netherlands
P Rump
B C J Hamel
Department of
Ophthalmology,
University Hospital
Nijmegen, PO Box
9101, 6500 HB
Nijmegen, The
Netherlands
A J L G Pinckers
Department of
Gynaecology and
Obstetrics, Catharina
Hospital, PO Box 1350,
5602 ZA Eindhoven,
The Netherlands
P A van Dop
Correspondence to:
Dr Hamel.
Received 10 January 1997
Revised version accepted for
publication 21 March 1997

Department of Human
Genetics, University
Hospital Nijmegen, PO
Box 9101, 6500 HB
Nijmegen, The
Netherlands
P Rump
B C J Hamel
Department of
Ophthalmology,
University Hospital
Nijmegen, PO Box
9101, 6500 HB
Nijmegen, The
Netherlands
A J L G Pinckers
Department of
Gynaecology and
Obstetrics, Catharina
Hospital, PO Box 1350,
5602 ZA Eindhoven,
The Netherlands
P A van Dop
Correspondence to:
Dr Hamel.
Received 10 January 1997
Revised version accepted for
publication 21 March 1997

Department of Human
Genetics, University
Hospital Nijmegen, PO
Box 9101, 6500 HB
Nijmegen, The
Netherlands
P Rump
B C J Hamel
Department of
Ophthalmology,
University Hospital
Nijmegen, PO Box
9101, 6500 HB
Nijmegen, The
Netherlands
A J L G Pinckers
Department of
Gynaecology and
Obstetrics, Catharina
Hospital, PO Box 1350,
5602 ZA Eindhoven,
The Netherlands
P A van Dop
Correspondence to:
Dr Hamel.
Received 10 January 1997
Revised version accepted for
publication 21 March 1997 
sterone undecanoate (Andriol(C), $80 \mathrm{mg} /$ day) after five years.

At the age of 30 years, an ophthalmological re-evaluation was performed at our clinic. At that time, his best corrected visual acuity was right $1 / 10$ and left $5 / 10$. The cornea, anterior segment, lens, and vitreous were normal. Ocular motility and pupillary responses were not disturbed. His eyelashes were relatively long. Fundoscopy showed choroidal atrophy in the peripapillary region, small retinal vessels, pink coloured optic discs, and bone spicule-like clumps of pigment deposition, together with atrophy of the retinal pigment epithelium and choriocapillaris in the mid peripheral areas. Intraocular pressure was normal in both eyes. On electroretinography some photopic rest activity was seen while the electro-oculogram was flat. Colour vision examination showed a combined blue-yellow and red-green defect with anomaloscopic diminished red sensitivity. Goldmann perimetry showed a large temporal scotoma and a decrease of central sensitivity bilaterally. The diagnosis of atypical chorioretinal dystrophy was made. The diagnosis of choroideremia was rejected because of the fundoscopy results and because his mother did not have fundoscopic signs of a choroideremia carrier.

CASE 2

The proband's younger sister was born after a normal pregnancy and delivery. She was first seen for primary amenorrhoea and poor sexual development at 21 years of age. On examination she was $175 \mathrm{~cm}$ (80th centile) in height and $58 \mathrm{~kg}$ (50th centile) in weight. Breast development was poor (Tanner 1-2) and only sparse pubic hair was present. Gynaecological examination showed hypoplastic external sexual organs. The vagina and cervix were very small and the uterus and adnexal structures were clinically undetectable. A complete blood count and routine blood chemistry profile showed no abnormalities. Endocrinological studies, however, showed hypogonadotrophic hypogonadism. The serum level of oestradiol was $0.05 \mathrm{nmol} / 1$ (normal $0.11-0.30$ ) and the concentrations of $\mathrm{LH}$ and FSH were 1.2 and $2.9 \mathrm{mIU} / \mathrm{ml}$, respectively (normal LH 3-120, FSH 5-16). There was no response to a single intravenous dose of $\mathrm{LH}$ releasing hormone. Serum concentrations of prolactin, cortisol, testosterone, TSH, triiodothyronine (T3), and T4 were all within normal limits. Pelvic ultrasound showed a very narrow and small uterus. It measured $0.5 \mathrm{~cm}$ in diameter and approximately $4.5 \mathrm{~cm}$ long. The adnexal structures could not be visualised properly. A diagnostic laparoscopy was performed and showed normal tubes and ovaries and a normal but small uterus. Radiographic evaluation of the sella turcica was unremarkable. The karyotype was $46, \mathrm{XX}$. Investigation of mitochondrial DNA did not show any deletions and the point mutations known for mitochondrial encephalomyopathy (MELAS) at position 3243 and 3252 and the point mutation known for neurogenic muscular weakness with ataxia and retinitis pigmentosa (NARP) at position 8993 were also excluded.

The patient was treated with an oral contraceptive (Trisequens $(\mathcal{C})$ and within three years of therapy breast development and pubic hair growth both reached Tanner stage 5 . The internal sexual organs however remained small and on temporary discontinuation of medication no menstrual periods occurred.

At the age of 24 years an ophthalmological evaluation was performed because she had noted that in the past three years her visual fields had narrowed progressively. Her best corrected visual acuity was right 5/10 and left $5 / 10$. Slit lamp examination of the anterior segments showed no abnormalities. Like her brother, she had relatively long eyelashes. Fundoscopy showed atrophic retinal pigment epithelium alterations, narrow retinal vessels, and bone spicule-like clumps of pigment deposition, very similar to the fundoscopic findings of her brother. On electoretinography some photopic rest activity was seen and the electrooculogram was flat. Colour vision examination showed a blue-yellow defect with anomaloscopic diminished red sensitivity. Visual field testing on a Goldmann perimeter showed a large ring scotoma and loss of central sensitivity bilaterally. The diagnosis was atypical chorioretinal dystrophy.

Since both brother and sister suffered from hypogonadotrophic hypogonadism and retinal degeneration, an inherited syndrome combining these two conditions had to be considered. Boucher-Neuhäuser syndrome was a likely candidate. Therefore, an extensive neurological evaluation of both patients was performed. Both the proband and his sister reported a slight disturbance of balance, first occurring during childhood. On examination a disturbed balance and gait was evidently present in both patients. Furthermore, marked dysdiadochokinesis of the hands and an ataxic heel to shin test was found. Neither patient was able to walk on their heels, suggesting some degree of muscle weakness. The deep tendon reflexes were just elicitable or absent and there was moderate pes cavus in both patients. A gaze evoked horizontal and vertical nystagmus was found in case 2 . A reduction of proprioceptive sensation, fingertip number writing perception, and dysstereognosis was found in the proband. Sensory examination was otherwise completely normal in both patients. Electromyogram showed broad complex motor unit potentials and decreased amplitudes. Nerve conduction velocities were not disturbed. MRI of the brain showed evident atrophy of the cerebellum, most pronounced at the vermis (fig 1).

The presence of spinocerebellar ataxia in addition to hypogonadotrophic hypogonadism and retinal degeneration confirmed the diagnosis of Boucher-Neuhäuser syndrome.

\section{FAMILY HISTORY}

The proband and his sister were born to healthy, non-consanguineous parents. In addition to these affected sibs, their parents had 

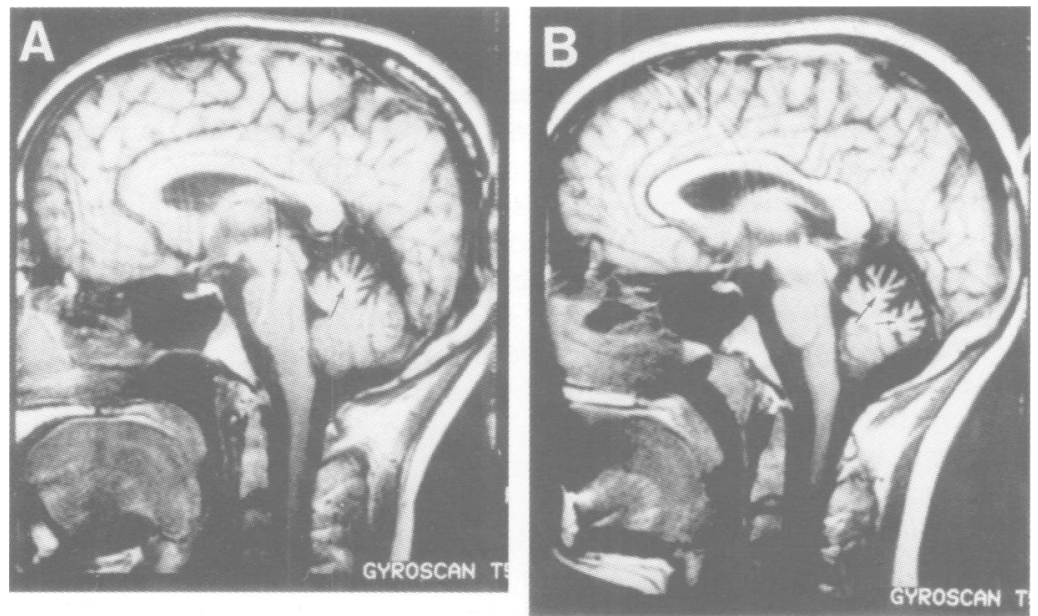

Figure $1 T 1$ weighted $M R I$ scan of the brain of the proband $(A)$ and his sister $(B)$ Cerebellar atrophy can be seen, most pronounced at the vermis (arrows). There is no atrophy of the base of the pons.

three sons, all in good health. The family history was otherwise unremarkable.

\section{Discussion}

The occurrence of retinal degeneration, hypogonadism, and cerebellar ataxia has been described in several syndromes with overlapping clinical features (for example, LaurenceMoon syndrome, Bardet-Biedl syndrome, Alström syndrome, Usher syndrome). However, these syndromes can be distinguished from Boucher-Neuhäuser syndrome since they are complicated by additional features like deafness, glucose intolerance, mental retardation, polydactyly, spastic paraplegia, and various dysmorphic features. ${ }^{11}{ }^{12}$ Disorders more similar to Boucher-Neuhäuser syndrome are infantile onset spinocerebellar ataxia (IOSCA), ${ }^{13}$ Oliver-McFarlane syndrome, ${ }^{14}$ and Holmes type ataxia $^{15}$ (table 1). Because of the overlapping features of Oliver-McFarlane syndrome, Holmes type ataxia, and Boucher-Neuhäuser syndrome one might even consider the possibility that they are clinical variants of a single disorder, particularly considering the fact that cerebellar hypoplasia was seen once in two sibs with Oliver-McFarlane syndrome. ${ }^{16}$

The association of all three disorders (chorioretinal degeneration, hypogonadotrophic hypogonadism, and cerebellar ataxia) in one patient and without additional abnormalities remains rare, however. In retrospect, one of the first papers on this subject was written in 1962 by Bernard-Weil and Endtz ${ }^{4}$ and before that Kapuscinski $^{17}$ and De $\mathrm{Mello}^{18}$ also reported cases with this triad. However, in these patients, mental retardation and choreoathethosis occurred and the type of hypogonadism was unknown. Lowenthal et al ${ }^{19}$ reported similar cases, but these patients also suffered from oligophrenia, anosmia, and anomalies of amino acid distribution. ${ }^{19}$ Considering the complicating features, the patients described in the latter three articles can probably not be identified as BoucherNeuhäuser syndrome, in contrast to a previous report. ${ }^{7}$ After further reviewing the published reports, at least 17 previously reported cases suffering from Boucher-Neuhäuser syndrome could be identified. ${ }^{1-10}$ Below, we list the most important clinical features (table 2) and discuss the variable presentation of this rare syndrome.

Besides the visual problems listed in table 2, several other symptoms like astigmatism, ${ }^{2}$ night blindness, ${ }^{3}$ photophobia, ${ }^{10}$ and disturbed depth perception ${ }^{3}$ have been described. The onset of these visual problems varied from the ages of 4 to 46 years. ${ }^{18}$ The main fundoscopic findings have been extensively described previously by Salvador et al. ${ }^{10}$ As stated before, ${ }^{7}$ the absence of bone spicule type pigmentation, macular oedema, and abnormal retinal vessels should differentiate it from typical retinitis pigmentosa. However, the diagnosis of retinitis pigmentosa was suggested in a few cases. ${ }^{36}$ Besides retinitis pigmentosa other diagnoses like (early) senile macular degeneration, ${ }^{24}$ retinal chorioretinitis, ${ }^{2}$ and choroideremia (present study) have been suggested. In addition, it seems that independent of the severity of the observed chorioretinal degeneration, the visual outcome varies between almost no loss of vision and complete blindness. This illustrates the variable presentation of the ophthalmological manifestations in Boucher-Neuhäuser syndrome.

In addition to the more common neurological findings in Boucher-Neuhäuser syndrome (table 2), dysmetria, ${ }^{2-467}$ dysdiadochokinesis, ${ }^{27}$ frontal headaches, ${ }^{2}$ and pes cavus ${ }^{126}$ have also been reported. Absent as well as increased deep tendon reflexes have been observed. The neurological symptoms are often slowly or non-progressive. Although in most cases the first neurological symptoms occurred in the third decade of life ${ }^{1-36-10}$ the onset of cerebellar ataxia started before 15 years of age in at least seven patients. ${ }^{25-7}$ The late onset or recognition of the ataxic symp-

\begin{tabular}{|c|c|c|c|c|c|c|}
\hline Features & $\begin{array}{l}\text { Boucher-Neuhäuser } \\
\text { syndrome }\end{array}$ & $I O S C A$ & $\begin{array}{l}\text { Holmes type } \\
\text { ataxia }\end{array}$ & $\begin{array}{l}\text { Oliver-McFarlane } \\
\text { syndrome }\end{array}$ & Case 1 & Case 2 \\
\hline Chorioretinal degeneration & + & - & $(+)$ & + & + & + \\
\hline $\begin{array}{l}\text { Cerebellar ataxia } \\
\text { Hypogonadotrophic }\end{array}$ & + & + & + & - & + & + \\
\hline $\begin{array}{l}\text { hypogonadism } \\
\text { Hypergonadotrophic }\end{array}$ & + & - & + & + & + & + \\
\hline hypogonadism & - & + & - & _ & _- & - \\
\hline Mental retardation & - & - & + & + & - & - \\
\hline Trichomegaly & - & - & - & + & + & + \\
\hline Alopecia & - & - & - & + & - & - \\
\hline Prenatal onset growth retardation & - & - & - & + & - & - \\
\hline
\end{tabular}

IOSCA = Infantile onset spinocerebellar ataxia. For references see text.

Retinal degeneration is seen in some patients with Holmes type ataxia. ${ }^{15}$ 
toms can make the diagnostic process very difficult and the dyad of hypogonadotrophic hypogonadism and retinal degeneration without additional symptoms does not conform to any diagnosis. In fact, we found only one report describing such an association. ${ }^{20}$ These authors described three sisters with hypogonadotrophic hypogonadism and retinitis pigmentosa. In addition to these sisters a prepubertal younger brother with retinitis pigmentosa was mentioned. Since the age of these patients did not exceed 22 years, it is not unlikely that the ataxic symptoms were recognised later in life, like the patients of the present study, but only a re-evaluation of these cases will prove this assumption to be correct.

In contrast to the ocular and ataxic symptoms, the endocrinological findings became evident at the time puberty was expected. Primary amenorrhoea, poor development of sexual organs, and sparse growth of secondary sexual hair prompted the diagnosis of hypogonadism. On testing, $\mathrm{LH}$ and $\mathrm{FSH}$ were deficient in all reported cases ${ }^{1-10}$ (present study). The absence of a response to $\mathrm{LH}$ releasing hormone injections strongly suggests a disturbed pituitary function ${ }^{5-8}$ (present study). The pattern of TSH and prolactin response to TRH plus the $G H$ response to GRF and insulin induced hypoglycaemia in some patients provide evidence for an additional involvement of the hypothalamus. ${ }^{58}$ In all patients these functional defects will result in infertility. Azoospermia has been reported in two male subjects. ${ }^{6}$ However, fertility can be restored by means of hormone substitution. In fact, two female patients with BoucherNeuhäuser syndrome gave birth to a child after such treatment. ${ }^{89}$

The association of Boucher-Neuhäuser syndrome with hypocalciuric hypercalcaemia was reported once in a female patient. ${ }^{8}$ As a result, she suffered from hair loss and several compression fractures. The cause of this hypocalciuric hypercalcaemia remained unknown, but the hypothesis that this disorder is part of the inherited syndrome seems unlikely. The patient was "assumed to be under postmenopausal state for over 10 years", and this lack of oestrogens seemed to play an important role in the pathogenesis. ${ }^{8}$ Furthermore, one sister of this patient with almost the same clinical history and symptoms had no hypercalcaemia. ${ }^{89}$

Besides the observation that the tissues involved are all of neuroectodermal origin, the exact link between the three disorders (chorioretinal degeneration, hypogonadotrophic hypogonadism, and cerebellar ataxia) remains unknown. All the reported cases provide evidence that this triad represents a specific pleiotropic single gene disorder with an autosomal recessive pattern of inheritance. Males and females are equally affected and all cases are sibs in a single generation with unaffected parents. In addition, consanguinity was present in three of the reported families ${ }^{28}$ and the karyotypes of all tested subjects were normal $^{13-8}$ (present study). However, the nature of the gene involved and the role it plays in the pathophysiology is still unknown. Recently, a single $5.5 \mathrm{~kb}$ mitochondrial DNA deletion was found in lymphocytes of a patient with ataxia, hypogonadism, choroidal dystrophy, and other symptoms. ${ }^{21}$ Mitochondrial metabolism deficiency in a patient with Holmes type ataxia and hypogonadism has been reported before ${ }^{15}$ and also the occurrence of ataxia and retinal degeneration in patients with mitochondrial myopathy has been reported. ${ }^{22}$ Investigation of mitochondrial DNA of one of the patients reported in the present study, however, did not show any abnormalities.

Until specific tests are available, the diagnosis of Boucher-Neuhäuser syndrome must be made on the basis of clinical findings. The identification and description of additional cases is important to improve our understanding of this rare syndrome and to distinguish between other disorders associating hypogonadism or retinal degeneration with ataxia.

Table 2 Clinical manifestations of Boucher-Neuhäuser syndrome*

\begin{tabular}{|c|c|c|c|c|c|c|}
\hline \multirow[b]{2}{*}{ Feature $(n=19)$} & \multicolumn{2}{|c|}{ Present } & \multicolumn{2}{|c|}{ Not present } & \multicolumn{2}{|c|}{ Unknown } \\
\hline & No & $\%$ & No & $\%$ & No & $\%$ \\
\hline $\begin{array}{l}\text { Complete triad } \\
\text { Ophthalmological findings }\end{array}$ & 16 & 84 & 1 & 5 & 2 & 11 \\
\hline $\begin{array}{l}\text { Ophthalmological findings } \\
\text { Loss of vision }\end{array}$ & 14 & & 21 \\
\hline Loss of colour discrimination & 5 & 26 & 1 & 5 & $\begin{array}{l}4 \\
12\end{array}$ & $\begin{array}{l}21 \\
63\end{array}$ \\
\hline (Ring) scotoma & 9 & 47 & 2 & $\begin{array}{l}11 \\
0\end{array}$ & 10 & 53 \\
\hline Retinal degeneration & 16 & 84 & $\begin{array}{l}0 \\
0\end{array}$ & 0 & 3 & 16 \\
\hline Disturbed ERG & 9 & 47 & 0 & 0 & 10 & 53 \\
\hline \multicolumn{7}{|l|}{ Neurological findings } \\
\hline Disturbed balance/gait & 17 & 89 & 0 & 0 & 2 & 11 \\
\hline Disturbed speech & 9 & 47 & 4 & 21 & 6 & 32 \\
\hline Nystagmus & 12 & 63 & 2 & 11 & 5 & 26 \\
\hline Cerebellar atrophy (CT/MRI) & 10 & 53 & 2 & 11 & 7 & 37 \\
\hline \multicolumn{7}{|l|}{ Endocrinological findings } \\
\hline Primary amenorrhoea (females) & 9 & 90 & 1 & 10 & 0 & 0 \\
\hline Hypoplastic sexual organs & 13 & 68 & 1 & 5 & 5 & 26 \\
\hline Sparse secondary sexual hair & 12 & 63 & 2 & 11 & 5 & 26 \\
\hline Low LH/FSH & 16 & 84 & 0 & 0 & 3 & 16 \\
\hline No response to LH-RH & 8 & 42 & 0 & 0 & 11 & 58 \\
\hline Normal intelligencet & 9 & 47 & 3 & 16 & 7 & 37 \\
\hline Normal karyotype & 13 & 68 & 0 & 0 & 6 & 32 \\
\hline
\end{tabular}

*Compiled from references 1 to 10 , including the cases presented in this study. ${ }^{\star}$ Compiled from references 1 to 10 , including the cases presented in this study.
†On all three occasions when intelligence was not considered normal, it was either attributed to the loss of vision or regarded as low 
We thank Dr H J Troelstra (Department of Neurology, Catharina Hospital, Eindhoven, The Netherlands) for his careful evaluation of both patients.

1 Boucher BJ, Gibberd FB. Familial ataxia, hypogonadism and retinal degeneration. Acta Neurol Scand 1969;45:50710.

2 Neuhäuser G, Opitz JM. Autosomal recessive syndrome of cerebellar ataxia and hypogonadotropic hypogonadism. Clin Genet 1975;7:426-34.

3 Limber ER, Bresnick GH, Lebovitz RM, Appen RE, Gilbert-Barness EF, Pauli RM. Spinocerebellar ataxia, Gilbert-Barness EF, Pauli RM. Spinocerebellar ataxia, (Boucher-Neuhäuser syndrome). Am $₹$ Med Genet 1989; 33:409-19.

4 Bernard-Weil E, Endtz LJ. Sur un cas familial de dégénération spino-cérébelleuse avec eunuchoïdisme hypogonadotrophique considérations pathogéniques et méthodlogiques. Nouv Presse Med 1962;70:524-6.

5 Fok ACK, Wong MC, Cheah JS. Syndrome of cerebellar ataxia and hypogonadotrophic hypogonadism: evidence for pituitary gonadotrophin deficiency. F Neurol Neurosurg Psychiatry 1989;52:407-9.

6 Baroncini A, Franco N, Forabosco A. A new family with chorioretinal dystrophy, spinocerebellar ataxia and hypogonadotropic hypogonadism (Boucher-Neuhäuser syndrome). Clin Genet 1991;39:274-7.

7 Erdem E, Kiratli H, Erba T, et al. Cerebellar ataxia associated with hypogonadotropic hypogonadism and chorioretinopathy: a poorly recognised association. Clin Neurol Neurosurg 1994;96:86-91.

8 Ichinose M, Tojo K, Nakayama M, Hasegawa T, Kawaguchi Y, Sakai O. Boucher-Neuhäuser syndrome associated with hypocalciuric hypercalcemia. Intern Med 1995;34:18-23.

9 Tojo K, Ichinose M, Nakayama M, et al. A new family of Boucher-Neuhäuser syndrome: coexistence of Holmes type cerebellar atrophy, hypogonadotropic hypogonadism and retinochoroidal degeneration: case reports and review of literature. Endocrine $\mathcal{F}$ 1995;42:367-76.

10 Salvador F, García-Arumí J, Corcóstegui B, Minoves T, Tarrus F. Ophthalmologic findings in a patient with cerebellar ataxia, hypogonadotropic hypogonadism, and chorioretinal dystrophy. Am $\mathcal{f}$ Ophthalmol 1995;120:241-4.
11 Green JS, Parfrey PS, Harnett JD, et al. The cardinal manifestations of Bardet-Biedl syndrome, a form of LaurenceMoon-Biedl syndrome. N Engl F Med 1989;321:1002-9.

12 Cantani A, Bellioni P, Bamonte G, Salvinelli F, Bamonte MT. Seven hereditary syndromes with pigmentary retinopathy a review and differential diagnosis. Clin Pediatr 1985 24:578-83.

13 Koskinen T, Pihko H, Voutilainen R. Primary hypogonadism in females with infantile onset spinocerebellar ataxia. Neuropediatrics 1995;26:263-6.

14 Sampson JR, Tolmie JL, Cant JS. Oliver McFarlane syndrome: a 25-year follow-up. Am $\mathcal{F}$ Med Genet 1989;34 199-201.

15 De Michele G, Filla A, Striano S, Rimoldi M, Campanella G. Heterogeneous findings in four cases of cerebellar ataxia associated with hypogonadism (Holmes' type ataxia). Clin Neurol Neurosurg 1993;95:23-8.

16 Helderman van der Ende ATJM, Laan LAEM, Massa G, Wittebol-Post D, Oosterwijk JC. Oliver-McFarlane syndrome in two sibs. Eur $\mathcal{F}$ Hum Genet 1996;4(suppl 1):132A.

17 Kapuscinski W. Über familiäre Aderhautentartung mit ataktischen Störungen. Ber Dtsch Ophtalmol Ges 1934;50:13-19.

$18 \mathrm{De}$ Mello AR. Heredo-degeneracao cerebelo-es-pinhal. Arch Bras Med 1943;33:88-100.

19 Lowenthal A, Bakaert J, Van Dessel F, Hauwaert J. Familial cerebellar ataxia with hypogonadism. F Neurol 1979;222: 75-80.

20 Chang RJ, Davidson BJ, Carlson HE, Lu JKH, Judd HL. Hypogonadotropic hypogonadism associated with retinitis pigmentosa in a female sibship: evidence for gonadotropin deficiency. f Clin Endocrinol Metab 1981;53:1179-85.

21 Casedemont J, Barrientos A, Genis D, Volpini V, Estivill X, Nunes V. Sporadic heteroplasmic single $5.5 \mathrm{~kb}$ mitochondrial DNA deletion in a patient with ataxia, hypogonadism and choroid dystrophy. Eur $\mathcal{F}$ Hum Genet 1996;4(suppl 1):101A.

22 Petty RKH, Harding AE, Morgan-Hughes JA. The clinical features of mitochondrial myopathy. Brain 1986;109:91538 . 